\title{
Study on the heat recovery of waste gas in printing plant
}

\author{
Yuhui $\mathrm{Di}^{1, \mathrm{a}}$, Linyuan Zhou ${ }^{2, \mathrm{~b}}$, Hui Yin ${ }^{1, \mathrm{c}}$ and Lijuan Wang ${ }^{1, \mathrm{~d}}$ \\ ${ }^{1}$ Xi'an Polytechnic University, Xi'an, China \\ ${ }^{2}$ Fushan District, Yantai City Yongda Street No. 720,Shandong, China \\ a2470836165@qq.com,,735310759@qq.com,,865857214@qq.com \\ d643547601@qq.com
}

Keywords: Printing plant, Organic exhaust gas, Heat recovery, Energy-saving

\begin{abstract}
The purpose of this study is to recycle the heat of waste gas in printing plant. Several heat recovery equipments are presented and analyzed. After comparing, the heat-pipe heat recovery equipment is found as the most effective equipment for the organic exhaust gas on the basis of its temperature. The mathematical model of heat recovery is provided and discussed. The conclusions are useful to increase the efficiency of heat recovery and save energy.
\end{abstract}

\section{Introduction}

The organic waste gas emitted by printing process causes great threat not only to the quality of printing production, but also to the work-men's health [1]. In addition, if the waste heat carried by the gas is emitted directly, the energy will be wasted and the air will be polluted. In this paper, taking the printing plant in the Xi'an as the example, the heat recovery technologies are used for the organic exhaust gas.

\section{Introduction of printing plant}

The printing plant is located in Xi'an, China. Its area is $72 \times 9 \mathrm{~m}^{2}$, and the height of lower chord is 5 $\mathrm{m}$. There are 9 printing machines inside, and whose sizes are $3.2 \times 2.6 \times 2.6 \mathrm{~m}^{3}$.

Since the dew-point temperature in Xi'an is very low, when the temperature of fresh air gets close to this value, the characteristics of paper and ink might be affected. Besides, the sensible heat of printing device is so much that it is kind of waste of energy. According to these factors, the heat recovery to compensate heating load is presented in this paper.

\section{Treatment Strategy}

Organic waste gas emitted by printing is collected by local exhauster hood [2], and then it is collected to exhaust duct through exhaust branch pipe. The organic gas distributes in the upper space with the aid of the rising heat flux. In order to collect the gas effectively, a negative pressure and upward exhaust hood are used. The size of the exhaust hood is $3.2 \times 3 \mathrm{~m}^{2}$, and it is made of galvanized steel plates. According to the height and the limited space in the printing plant, the distance between the hood face and the top of equipment is $0.4 \mathrm{~m}$, and the distance between the hood face and the exhaust gas source is about $1 \mathrm{~m}$. The vent size of the plant is $1.48 \times 1.55 \mathrm{~m}^{2}$, with the total exhaust air capacity of $63000 \mathrm{~m}^{3} / \mathrm{h}$. The emission concentration of the organic waste gas can not meet the second level emission standards of the "Comprehensive Discharge Standard of 
Atmospheric Pollutants" [3]. So it cannot be released to atmosphere without any treatment. If the catalytic oxidation is used to treat the exhaust air, the bottleneck will be wasted energy because of the huge quality of exhaust air with low concentration organic gas [4]. In this paper, the technology of adsorption concentration combined with catalytic oxidation [5] is adopted to treat the exhaust air. Its technological process is shown in Figure 1.

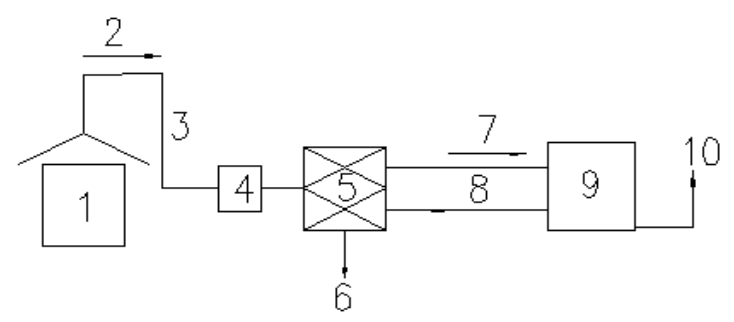

Figure 1. Treatment process about printing organic waste gas.

1-printing device, 2-low concentration VOCs, 3-exhaust manifold, 4-prefilter, 5-adsorption bed, 6-clean air, 7-high concentration VOCs, 8-hot flue for desorption, 9-equipment for catalytic oxidation, and 10-emission gas

Compared with the direct catalytic oxidation, the technology of adsorption concentration combined with catalytic oxidation is more efficient. However, the high temperature of emission gas still leads to a huge waste of latent heat and sensible heat. If the heat is directly discharged into the atmosphere, the thermal pollution will happen. So the technology of heat recovery should be introduced in next chapter.

\section{Technologies of Heat Recovery}

General plan of heat recovery. According to the related research results, the temperature of treated organic waste gas can reach $400 \sim 500{ }^{\circ} \mathrm{C}$ [6]. Combined with the organic waste gas treatment process of the printing plant, the residual heat of the emission gas will be used for heating or reheating. In this way, the temperature of the emission gas will be reduced, and the heating energy consumption will be cut down dramatically [7]. The principle of the heat recovery is shown in Figure 2.

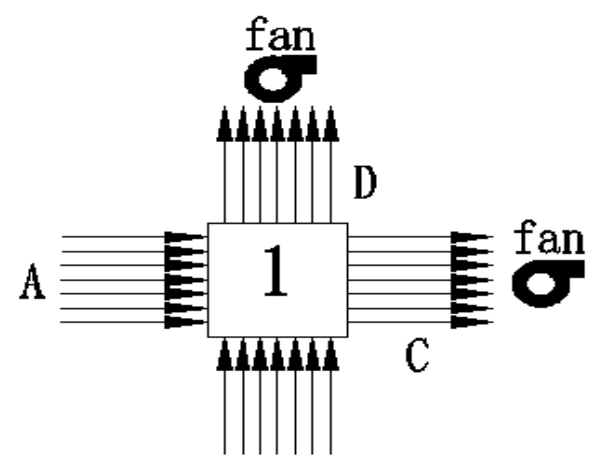

B

Figure 2. The principle of heat recovery.

1-heat recovery unit; A-new air with low temperature, B-high temperature emission gas, C- supply air with middle temperature, and D-middle temperature exhaust air.

In Figure 2, the heat recovery is an air to air heat recovery system. The heat transfers from high temperature gas to low temperature fresh air in the unit. The efficiency of heat exchange is 
determined by the flow rate, flux, the construction of heat recovery equipment, etc.

Comparison of recovery equipments. The heat recovery device can be divided into full heat recovery unit and sensible heat recovery device. It also can be divided into plate type, plate-fin type, runner type and heat-pipe type according to the structure [8]. The characteristics of them are shown in Table 1.

Table 1 . The characteristics of heat recovery equipments

\begin{tabular}{ll}
\hline Type & \multicolumn{1}{c}{ Characteristics } \\
\hline Plate & $\begin{array}{l}\text { static type; used for sensible heat recovery; simple structure; heat } \\
\text { recovery efficiency from } 40-60 \% .\end{array}$ \\
Plate-pin & $\begin{array}{l}\text { added fin to plate device; efficiency improves with the increase of heat } \\
\text { exchange area; used for general heat recovery with low energy } \\
\text { consumption. }\end{array}$ \\
Runner & $\begin{array}{l}\text { rotated device; can be used for large air flow; high efficiency; no } \\
\text { pollution to new air; driven by electrical machine; complex structure. }\end{array}$ \\
& $\begin{array}{l}\text { suitable for heat recovery of exhaust air whose temperature is lower } \\
\text { than } 400 ~ 500^{\circ} \mathrm{C} \text {; easy-constructed; convenient for maintaining; high }\end{array}$ \\
& $\begin{array}{l}\text { efficient and no energy consumption for large pin and heat exchange } \\
\text { area device; no pollution to new are. }\end{array}$
\end{tabular}

Considering the temperature of organic waste gas, structure, heat recovery efficiency, operation and other factors, the heat-pipe heat recovery equipment is chosen to reheat fresh air. Figure 3 shows the structure of heat-pipe heat exchanger. The fin is installed in the outer surface of heat pipe to increase the heat exchange area. A baffle in the middle of the device is used to prevent waste gas mixing with fresh air.

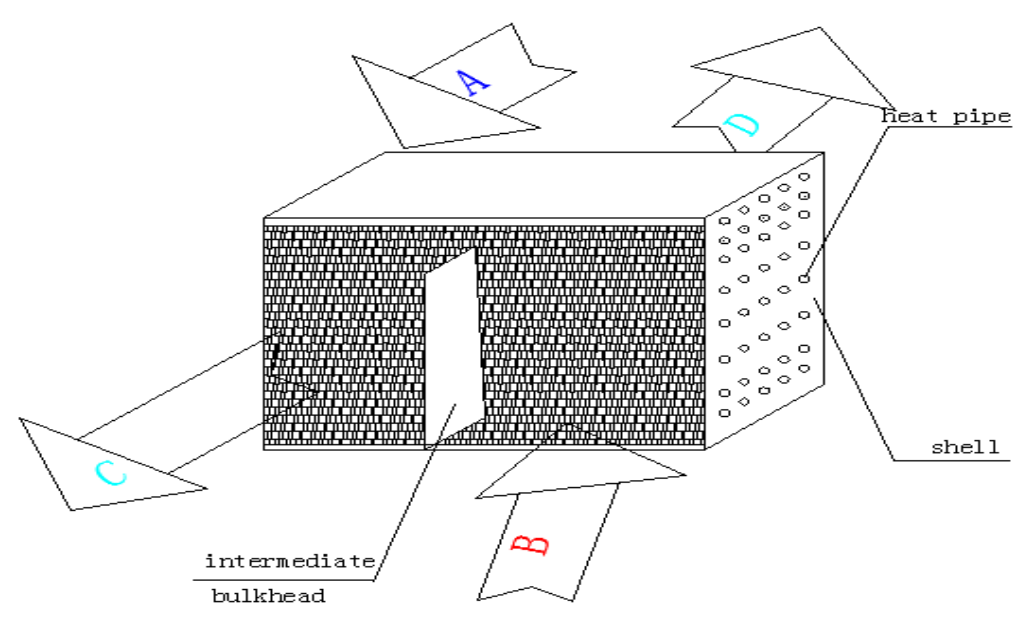

Figure 3. The heat-pipe equipment for sensible heat recovery

On the basis of heat transfer knowledge, the heat exchange between fresh air and high temperature emission gas can be presented as,

$$
Q_{e x}=K \cdot A \cdot \Delta T
$$

where $\mathrm{K}$ is coefficient of heat transfer, $\mathrm{A}$ is heat exchange area, and $\Delta \mathrm{T}$ is logarithmic mean temperature difference [9]. 


$$
\Delta T=\frac{\left(t_{w i}-t_{x o}\right)-\left(t_{w o}-t_{x i}\right)}{\ln \frac{t_{w i}-t_{x o}}{t_{w o}-t_{x i}}}
$$

where $t_{w i}$ is inlet temperature of emission gas, $t_{x i}$ is inlet temperature of fresh air, $t_{w o}$ is outlet temperature of emission gas, and $t_{x o}$ is outlet temperature of reheat air.

The heat balance equation is

$$
Q_{e x}=M_{w} c_{w}\left(t_{w i}-t_{w o}\right)=M_{x} c_{x}\left(t_{x o}-t_{x i}\right)
$$

where $M_{\mathrm{w}}$ is the mass flow rate of emission gas, $M_{x}$ is the mass flow rate of fresh air, $c_{w}$ is the specific heat capacity of emission gas, and $c_{w}$ is the specific heat capacity of fresh air.

The efficiency of sensible heat recovery is

$$
\eta=\frac{t_{x o}-t_{x i}}{t_{w i}-t_{x i}} \times 100 \%
$$

Substitute Eq. (1), Eq. (2) and Eq. (3) into Eq. (4), and the following equation can be obtained.

$$
\eta=\frac{1-\exp \left[(R-1) \frac{K \cdot A}{M_{x} c_{x}}\right]}{1-R \cdot \exp \left[(R-1) \frac{K \cdot A}{M_{x} c_{x}}\right]} \times 100 \%
$$

where $\mathrm{R}$ is water equivalent ratio.

$$
R=\frac{M_{x} c_{x}}{M_{w} c_{w}}
$$

Eq. (5) shows that the efficiency of the heat-pipe heat recovery equipment has relationship with the heat transfer coefficient, heat transfer area, the quantity and specific heat capacity of the gas. So the heat recovery efficiency can be raised by installing fin or regulating the flow ratio.

\section{Conclusions}

In order to treat the organic waste gas in the printing plant, the characteristics of several equipments is compared. The heat-pipe heat recovery device is the best and chosen to heat fresh air. Besides, the mathematical model of heat transfer process is provided and its efficiency is analyzed.

The sensible heat recovery is analyzed in this paper. If the whole heat recovery technology can be taken into the heat recovery, it will be more significant. It needs further research is in need to explore the technology of increasing the recycled heat for full year operating mode.

\section{Acknowledgement}

This work was financially supported by the Shaanxi Provincial Science and Technology Department Industrialization Project (No. 15JF017). 


\section{References}

[1] H. Ren and D. Yunfei: Analysis on Comprehensive Utilization Scheme of Waste Heat of Centralize Discharge System of the Enameled-wire Machine Group. Building Energy \& Environment, Vol. 31(2012), p 76-77.

[2] H. Xiang, in: Air Conditioning Engineering, edtied by China Machine Publishing, Beijing(2006 ) , in press.

[3] K. J. Kim, J. Kim, YS. Son and S.G. Chu: Advanced oxidation of aromatic VOCs using a pilot system with electron beam-catalyst coupling. Radiation Physics \& Chemistry, Vol. 81(2012), p $561-565$.

[4] M. Li: Ventilation and purification for a fiberglass fabric workshop. Heating Ventilating \& Air Conditioning, Vol. 35(2005), p 72-73.

[5] S. Jianhua and L.Weiping: Removal of VOCs from waste gases of printing process using ACF absorbers. Techniques and Equipment for Environmental Pollution Control, Vol. 7(2006), p $117-120$.

[6] S. Zhenyu and L. Min: Exhaust air heat recovery for a cigarette factory in hot summer and cold winter zone. Heating Ventilating \& Air Conditioning, Vol. 43(2013), p 87-90.

[7] S. Yijian, in: Concise Ventilation Design Manual, edtied by China Building Industry Publishing, Beijing(2008), in press.

[8] X. Peng, C. Fangyuan and H. Qingming: Application of combined treatment process for purification of VOCs in gravure printing. Light Industry Machinery, Vol. 27(2009), p 107-111.

[9] Y. Shiming and T. Wenquan, in: Heat Transfer, edtied by Higher Education Publishing, Beijing(2006),in press. 